\title{
POSTOPERATIVE MUSCLE SPASM IN A CHILD WITH CEREBRAL PALSY: A CASE REPORT
}

\author{
K. Sanmuga Piriya ${ }^{1}$, K. Suresh Kumar², N. Mohamud Iqbal ${ }^{3}$, R. Prasanna Kumar ${ }^{4}$, A. Sivashanmugham ${ }^{5}$
}

\section{HOW TO CITE THIS ARTICLE:}

K. Sanmuga Piriya, K. Suresh Kumar, N. Mohamud Iqbal, R. Prasanna kumar, A. Sivashanmugham. "Postoperative Muscle Spasm in a Child with Cerebral Palsy: A Case Report". Journal of Evolution of Medical and Dental Sciences 2014; Vol. 3, Issue 57, October 30; Page: 13043-13046, DOI: 10.14260/jemds/2014/3732

\begin{abstract}
Cerebral palsy is a non-progressive motor disorder which occurs due to hypoxic insult to fetus during perinatal period. These children often present for elective surgical procedures to correct various deformities. Peri-operative care of a child with cerebral palsy is a real challenge to the anaesthetics because of associated comorbidities. Yet another problem in these patients is behavior abnormality and difficulty in communication. Therefore regional anaesthesia is usually combined with general anaesthesia and not used alone. The two most important anaesthetics concerns in these patients are hypothermia and post-operative muscle spasm. Epidural analgesia is the most effective method of post-operative pain relief. Even though opioids can be used for post-operative analgesia, clonidine is more effective in relieving post-operative muscle spasm. In this case report we have discussed about the anesthetic management and postoperative muscle spasm in a child with cerebral palsy.
\end{abstract}

KEYWORDS: Cerebral Palsy, Epidural Clonidine, Post-Operative Muscle Spasm.

INTRODUCTION: Cerebral palsy is a non-progressive motor disorder of cerebral origin. The incidence is 2 per 100 live births. ${ }^{[1]}$ Anesthetic management of these patients has special concerns due to associated co-morbidities. Most of these children come for surgical correction of their deformity. This case report highlights the anesthetic management of a child with cerebral palsy who came for contracture release and about post-operative muscle spasm which is one of the causes for severe pain in the postoperative period.

CASE REPORT: An 11 yrs. old female child diagnosed as a case of spastic diplegic cerebral palsy with contractures in both lower limbs was planned for surgical correction of the deformity. She is on oral Baclofen 10mg twice daily for the past 6 months. On examination, she was thin built and malnourished with a weight of $15 \mathrm{~kg}$. Her airway, respiratory and cardiovascular systems were examined to be normal. She had spasticity of both the lower limbs with scissoring of legs. There was no spinal deformity. Her investigations were found to be within normal limits.

After obtaining written informed consent from parents, the child was shifted to the operation room and all routine monitors (NIBP, continuous ECG, $\mathrm{SpO}_{2}$, temperature) were connected. IV line was secured and the child was premedicated with Inj. Fentanyl (20 mcg IV), and Inj. Glycopyrrolate (0.1 mg IV). After sedating with Inj. Propofol (15 mg IV), 18G epidural catheter was secured in $\mathrm{L}_{3}-\mathrm{L}_{4}$ interspace and catheter was fixed at $6 \mathrm{~cm}$ at skin level and sterile dressing was done.

After negative aspiration a test dose of $2 \mathrm{ml}$ of $2 \%$ lignocaine with adrenaline (1:200000) was given. Epidural was activated using $0.5 \%$ bupivacaine with $7 \mathrm{ml}$ and the airway was secured with 2.5 size classic LMA and the child was maintained on spontaneous ventilation with $\mathrm{O}_{2}, \mathrm{~N}_{2} \mathrm{O}$ and sevoflurane $1 \%$. The surgery lasted for approximately $1 \mathrm{hr}$. $30 \mathrm{mints}$ and POP was applied in both the legs at the end of the surgery. 
Intraoperative period was uneventful. LMA removed in fully awake state and patient was shifted to the recovery room. In the immediate post-operative period, the child became restless with the complaints of severe pain in both the legs. So epidural top-up was given with $1 \%$ ropivacaine $(3 \mathrm{ml})$ which did not relieve her pain. So additional $2 \mathrm{ml}$ of $1 \%$ ropivacaine was given which was also not relieving her pain.

The possibility of postoperative muscle spasm was thought of and we decided to give epidural clonidine. $7.5 \mu \mathrm{g}$ of clonidine $(2.5 \mathrm{mcg} / \mathrm{ml})$ was given through the epidural catheter, which relieved her pain. Then epidural infusion was started with $0.1 \%$ ropivacaine and $2.5 \mathrm{mcg} / \mathrm{ml}$ of clonidine at a rate of $3 \mathrm{ml} / \mathrm{hr}$. after which the child was comfortable. The infusion was continued for two days.

DISCUSSION: Managing a child with cerebral palsy is a real challenge to an anesthetist starting from preoperative evaluation till the postoperative care. The very important anesthetic considerations are,

i) Behavioural abnormality,

ii) Positioning and deformity,

iii) Gastro-oesophageal reflux,

iv) Hypothermia, and

v) Postoperative muscle spasm.

Because of behavioural abnormality and difficulty in communication, regional anaesthesia is usually used as an adjunct to general anaesthesia and not used alone. Due to the associated skeletal deformity regional anaesthesia and positioning might be difficult. Gastro-oesophageal reflux is very often associated with cerebral palsy but very difficult to elicit. History of frequent night awakening is suggestive of GERD. ${ }^{[2]}$ Hence these patients are more prone for aspiration pneumonitis which is the most common cause of mortality in these patients. ${ }^{[3]}$

Recurrent respiratory infection is more common due to poor immunity and aspiration. Preoperative control of infection with antibiotics and chest physiotherapy will help in better outcome. Children with cerebral palsy are more for hypothermia because of poor muscle fat and also due to hypothalamic dysfunction. ${ }^{[4]}$ Temperature monitoring is mandatory in these patients. Using forced air warmers and warm blankets will prevent hypothermia.

Multiple drug therapy especially anti-convulsants (Diazepam, valproate) and anti-spasmodic (Botulinum toxin, Baclofen) agents are prescribed to these children which can interact with anaesthetic agents resulting in delayed recovery. Botulinum toxin will potentiate the action of muscle relaxants. Sudden withdrawal of Baclofen in the perioperative period can result in seizures.

POSTOPERATIVE MUSCLE SPASM: This is a very common cause for severe pain in the post operative period following contracture release. The incidence is usually underestimated. Surgically exposed nerve endings and muscle stretch receptors activate local spinal reflexes resulting in muscle spasm.[4]

MANAGEMENT OF MUSCLE SPASM: BENZODIAZEPINES: Diazepam administered intravenously is very often used to relieve spasm but the dose required is very high which results in sedation and delayed recovery. ${ }^{[2]}$ 
BACLOFEN: Baclofen is a centrally acting muscle relaxant. It acts on GABA-B receptors in the dorsal horn of spinal cord and is very effective in relieving muscle spasms. Oral baclofen is poorly absorbed hence not routinely used in the perioperative period. Baclofen is very effective in relieving muscle spasm when administered intrathecally.[5] The effect is seen within 24-48 hrs. Sudden withdrawal of baclofen can result in seizures.

BOTULINUM TOXIN: Botulinum toxin is given as targeted intramuscular injection into the affected group of muscles. The injected toxin moves retrogradely and reaches the neuromuscular junction. It acts by presynaptic inhibition of Ach release in the NM junction. The maximum dose is 12 units $/ \mathrm{kg} .{ }^{[2]}$ Clinical effect is seen after 1 week and the effect lasts for 4 months. Since it takes 1 week for the onset, it has to be given 1 week prior to surgery to prevent postoperative muscle spasm. [6] It potentiates the action of muscle relaxants.

OTHER DRUGS: Tizanidine, dandrolene, vigabatrin are also used in the treatment of muscle spasm.

SELECTIVE DORSAL RHIZOTOMY: It is a neurosurgical procedure done in patients who are not responding to medical therapy.Evoked potentials are used to identify the contributing rootlets and subsequently divided.[7]

EPIDURAL ANAESTHESIA: It is the most effective method in the immediate post-operative period. Local anaesthetic along with adjuvants like opioids and $\alpha 2$ agonist (clonidine, dexmeditomidene) is routinely used. Clonidine is more effective in relieving muscle spasm compared to opioids.[2] Clonidine potentiates local anaesthetic action, has intrinsic local anaesthetic property, acts similar to inhibitory interneuron thereby relieving spasm. ${ }^{[8]}$ Moreover it does not produce nausea and vomiting as compared to opioids.

CONCLUSION: Management of patients with cerebral palsy needs special attention and a thorough knowledge about the possible perioperative complications and its management will result in better patient outcome. In the post-operative period the possibility of muscle spasm should be kept in mind as a cause of severe pain and also the fact that clonidine is very effective in relieving it.

\section{REFERENCES:}

1. OP Ghai, Vinod K Paul, Arvind Bagga editors. Essential Pediatrics: Cerebral palsy. $7^{\text {th }}$ ed.India: CBS publishers; 2009.

2. Nolan G A, Chalkiadis J Low, C A Olesch, T C K Brown. gastro oesophageal reflux in cerebral palsy. Anaesthesia. 2000; 55: 32-41.

3. Evans PM, Evans SJ, Alberman E. Cerebral palsy: why we must plan for survival. Archives of Disease in Childhood 1990; 65: 1329-33.

4. Dr Mimi Darcey. Hypothermia in cerebral palsy. Anaesthetic management of patients with cerebral palsy. ATOTW 196; 2010: 1-7.

5. Albright AL. Intrathecal baclofen in cerebral palsy movement disorders. Journal of Child Neurology, 1996; 11 (Suppl. 1): S29-35. 


\section{CASE REPORT}

6. Barwood S, Baillieu C, Brereton K. Analgesic effects of botulinum toxin A: randomized, placebocontrolled clinical trial. Dev Med Child Neurol. 2000; 42: 116-121.

7. John Aker, David J Anderson. Perioperative care of patients with cerebral palsy. AANA Journal, 2007; 75: 65-72.

8. Eisenachl. Epidural clonidine mechanism of action. Anaesthesiology 1996; 85: 655.

\section{AUTHORS:}

1. K. Sanmuga Piriya

2. K. Suresh Kumar

3. N. Mohamud Iqbal

4. R. Prasanna kumar

5. A. Sivashanmugham

\section{PARTICULARS OF CONTRIBUTORS:}

1. Post Graduate Student, Department of Anaesthesiology, Sri Manakula Vinayagar Medical College, Pondicherry.

2. Associate Professor, Department of Anaesthesiology, Sri Manakula Vinayagar Medical College, Pondicherry.

3. Professor, Department of Anaesthesiology, Sri Manakula Vinayagar Medical College, Pondicherry.
4. Assistant Professor, Department of Anaesthesiology, Sri Manakula Vinayagar Medical College, Pondicherry.

5. Post Graduate student, Department of Anaesthesiology, Sri Manakula Vinayagar Medical College, Pondicherry.

NAME ADDRESS EMAIL ID OF THE CORRESPONDING AUTHOR:

Dr. K. Sanmuga Piriya, \# 7, Nethaji Street, Sorna Nagar, Ariyankuppam, Pondicherry-605007

Email: piriyakannan@gmail.com

Date of Submission: 17/10/2014. Date of Peer Review: 18/10/2014. Date of Acceptance: 27/10/2014. Date of Publishing: 30/10/2014. 